\title{
What is Transcendental Information? A Conceptual Paper
}

\author{
Yazdan Mansourian \\ School of Information Studies, \\ Charles Sturt University, Australia \\ ymansourian@csu.edu.au
}

\begin{abstract}
Background. Until recently, information behaviour scholars have mainly focused on the workplace or educational settings, and defined information as either a tool for problem solving or a means to satisfy needs. This, however, only represents a partial picture of a larger horizon. In some arenas of life, such as serious leisure, people do not seek information to necessarily solve a problem or satisfy an urgent need. They look for information to enjoy a hobby or participate in an entirely voluntary activity.

Objectives. The paper introduces transcendental information as a subjective and contextual concept to provide insights on lesser explored corners of the information behaviour scholarship. This concept is compared with existing theories and concepts in the information behaviour area.

Method. This conceptual paper is based on a critical literature review of human information behaviour, and reflects on some key concepts in the field, including the nature of information, information needs, information seeking and sharing. The paper also provides a selective literature review of the serious leisure perspective to contextualise the analysis.

Results. It is found that transcendental information usually has an aesthetic and intellectual essence. It may be expressed in various imaginative forms and can appear in different non-textual and embedded formats. Moreover, it can generate joyful and inspiring impacts. The paper refers to serious leisure as an exemplary setting to contextualise transcendental information within a relevant and wellestablished theoretical framework.
\end{abstract}

\section{INTRODUCTION}

The majority of studies in human information behaviour make certain assumptions about everyday life matters that affect our overall understanding of the role of information in society. Our perception of information needs, information seeking and sharing has been formed primarily based on these assumptions, and therefore may not hold true in all arenas of life. As a result, our knowledge about human information behaviour remains incomplete and even inaccurate in some cases. This paper argues that there is a necessity to reconsider our leading assumptions to gain a fresh understanding of the nature of information and, in particular, to see the less evident parts of it. To achieve this goal the paper introduces transcendental information as a tentative term to represent various forms of information which exist beyond the common assumptions.

What then are these assumptions? The first problematic one is the assumption of information overload. Of course it is true that the volume of information production is greater 
than ever in human history. However, it does not mean that everyone faces information overload. Many groups of people suffer from information scarcity, and struggle to find the information they are looking for. The concept of digital divide is an example (Van Dijk \& Hacker, 2003; Delello \& McWhorter, 2017) which highlights inequitable access to information across the world.

Furthermore, we suppose that human activities are entirely rational, and an information item must necessarily help us to address a problem. This is not the case most of the time. In our everyday life, we are just partly rational and mainly emotional. This fact has already been confirmed in many fields, such as decision making. According to the well-known theory of bounded rationality and satisficing, developed by Herbert Simon in 1955, in real life due to time constraints and cognitive limitations, it is not always possible to explore all existing decision outcomes to make fully reasoned and purely rational decisions. Therefore, we have to decide rationally within practical boundaries or within the limits of bounded rationality (Simon, 1955). Similarly, Zipf's (1949) principle of least effort reminds us that if there are different routes to achieve a goal, people tend to select the easiest option involving the least effort which is not always the most rational one.

Another supposition is that everyone is very busy, and shortage of time is a problem globally. On the contrary, there are many people around the world with plenty of free time, and they do not know what to do with their boredom and idleness. Therefore, one cannot assume that time pressure is a reality for everyone. Furthermore, the assumption about the importance of work compared with leisure is problematic in many ways. It is a common supposition that work is everyone's first priority in modern societies. Accordingly, having fun is not really that essential. Though we need to earn a living, work is not the ultimate goal of life. We need sufficient time to relax and enjoy our leisure to maintain our physical, mental and emotional well-being.

Finally, we assume that an information item is valuable only if it addresses a problem or reduces uncertainty; otherwise it is useless. This assumption is not always true. Sometimes people want information to simply satisfy their curiosity, and this is still important. For instance, people who search for music-related information do not require it for solving their problems. They do not even need it to deal with a knowledge gap. They just want it for enjoying their preferred music (Shuker, 2004; LaPlante \& Downie, 2006). Similarly, Margree et al. (2014) who studied the information behaviour of music record collectors reported:

For all participants, the search for new items to add to the collection was a central and lifelong activity, linked to their love of, and enjoyment in listening to, music.

In summary, information researchers should re-examine the existing assumptions for information access and usage in contemporary society. This paper argues that to gain a more holistic view of the nature of information, they should consider all aspects of information seeking, including non-work related information behaviour beyond everyday life information seeking.

To achieve this goal, this paper reviews current knowledge on the essence of information, and cites a number of theoretical frameworks that have already taken major steps in changing the way we comprehend information, for example, Belkin's (1980) anomalous state of knowledge theory, Savolainen's (1995) everyday life information seeking framework, and Dervin's (1983) sense-making framework. Thereafter, the paper proposes the concept of transcendental information as a type of information that can be considered in everyday life information seeking research and theories as a new perspective. 


\section{FUNCTIONS OF INFORMATION}

A quick review of the literature indicates that most scholars in information science defined information either as a tool for problem solving or as a source for satisfying basic information needs. Also, information as a pattern of meaningful data that enables people to make an informed decision, has been well cited (Case \& Given, 2016). In fact, the utility of information in practice and the intentionality of the information seeker to purposefully look for information are pivotal points in defining this phenomenon. Moreover, there is an emphasis on the cognitive aspects of this phenomenon, and uncertainty reduction plays a key role here. Case and Given (2016, p. 76) reviewed the definitions of the concept of information, and reported:

The most common types of definitions that have emerged assume that information is something that either reduces uncertainty or changes of one's image of reality.

One of the first theories with this approach is Belkin's $(1978,1980 \& 2005)$ anomalous state of knowledge (ASK) theory. Based on his theory, the main stimulus of information seeking is an anomalous state of knowledge which exists when an information user apprehends an anomaly - a gap or uncertainty - in his or her knowledge of a phenomenon, situation, event or topic. In the next stage, the information seeker might try to address the uncertainty by looking for new information. Meanwhile, he or she keeps assessing and monitoring the situation to see whether the anomaly has been fixed. This process continues to the point when the information user fixes the anomaly, or gives up from exhaustion (Case \& Given, 2016).

Another seminal work is Dervin's (1983, 1992 \& 1998) sense-making framework. She also focused on the uncertainty reduction process, and believed that the paradigm of inputoutput relationship between the user and information did not explain the reality of information seeking and usage. This is because when people search for information, they construct sense and make meaning rather than be passive receivers of information. From this perspective, desire for information begins with some questions to make sense of the situation. Communication is central to the process of bridging the gap and constructing meaning. Therefore, sense making is the process and sense is the product (Dervin, 1983).

Nonetheless, this is not the whole story - it still depicts a partial picture of a larger horizon. In many hedonistic aspects of life such as leisure activities, entertainment, music, social media, sport, and gaming, people usually do not seek or share information to necessarily reduce their uncertainty about something specific, solve a particular problem or satisfy an urgent necessity. They seek information simply because they enjoy learning something new, and this joy of discovering information is their main motivation. On the other hand, the concept of uncertainty is not just about a problem or practical situation: a gap in understanding is relevant in this context, for example, what we would like to do in our leisure time.

\section{IMPORTANCE OF INFORMATION IN HIGHER LEVELS OF LIFE}

Kari and Hartel (2007) and Fulton (2009 \& 2016) are amongst a few scholars who criticised the existing negative mentality in information science research, and called for further research 
on information behaviour in the joyful and insightful aspects of life. Kari and Hartel (2007, p. 1131) reported:

The discipline of information science has traditionally favored lower contexts-like everyday life and problem solving - that are neutral or even negative by nature. In contrast, the neglected higher things in life are pleasurable or profound phenomena, experiences, or activities that transcend the daily grind.

They believed information researchers focused too much on the negative and problematic aspects of information behavior and too little on the positive and pleasurable perspectives. As a result, the current image of information behaviour is biased towards the negative perspective, and there is a need to redress the balance in this area. Fulton (2009) called for further research to illuminate the potential of positive affect in information behaviour in different settings.

\section{SERIOUS LEISURE AS A HIGHER LEVEL CONTEXT}

Serious leisure is one of the fertile grounds for exploring the positive perspective of information behaviour. Serious leisure is a sociological term coined by Robert Stebbins in 1982, and it refers to a wide range of leisure activities that are sufficiently challenging and adequately enjoyable that people freely choose to carry out in their free time for a long period (Stebbins, $1982 \&$ 1992). The level of involvement with the chosen activity-which might be an indoor or outdoor hobby or a voluntary engagement - is substantial in serious leisure, and usually it requires genuine dedication and specific skills. This kind of leisure is distinguished from other kinds, such as casual leisure like watching TV or reading fiction which does not entail specific knowledge and skills, or project-based leisure which is usually a one-off commitment such as planning a wedding ceremony, festival or cultural event (Hartel, 2014). Serious leisure typically needs perseverance, development of special skills, unique ethos among participants and developing leisure identity (Stebbins, 1992 \& 2001).

In recent years, a number of scholars studied the informational and knowledge development aspects of serious leisure in different hobbies and volunteer activities such as gourmet cooking (Hartel, 2010), environmental activist (Savolainen, 2007), volunteer fund raising (Lee \& Kim, 2018), rubber duck collecting (Lee \& Trace, 2009), liberal arts (Hartel, 2014; Jones \& Symon, 2001), birdwatching (Lee et al., 2015; Scott \& Lee, 2010), gardening (Cheng et al., 2017), urban exploration (Fulton, 2017), museum visiting (Skov, 2013), genealogy and family history (Hershkovitz \& Hardof-Jaffe, 2017), ultra-running (Gorichanaz, 2015 \& 2017), music record collecting (Shuker 2004; LaPlante \& Downie, 2006; Margree et al., 2014) and adventure tourism (Løseth, 2018).

Serious leisure activities are rewarding. They not only bring joy and pleasure to the participants, but also provide a wide range of personal and social benefits. Personal enrichment, self-actualization, self-expression, enhancing self-image, self-gratification and forming identification are just a few examples from a long list of benefits (Ryu \& Heo, 2017; Miller, 2018; Lee \& Ewert, 2019; Bowness, 2020). Experiencing positive psychological wellbeing and transforming the lives of participants are other findings reported in the literature (Iwasaki, 2007; Lee \& Payne, 2016; Heo et al., 2018).

Moreover, previous research has shown that serious leisure can be useful in reducing stress, decreasing burnout, providing enjoyable distraction, creating social support, and generating optimism through pleasant experiences and facing challenges (Caldwell, 2005; Shupe \& Gagné, 2016; Falcous, 2017; Chang, 2017; Rahikainen, 2020). Similarly, there were 
social rewards for different groups of participants who collaborated with one another in group activities. For instance, group accomplishments celebrated in festivals, artistic exhibitions and so on were amongst the list of social rewards (Lee, 2020). Recent studies showed that in addition to the above-mentioned benefits, serious leisure may bring financial profits to the participants (Lim, 2020).

\section{INFORMATION SEEKING FOR DIFFERENT PURPOSES}

People usually look for information as a result of various motivations to fulfil meaningful purposes. The motivations vary on a wide scale, from satisfying simple curiosity to addressing sophisticated research questions, and these are all various kinds of information gaps. Similarly, the task might be different ranging from answering simple and basic questions such as fact-based questions, to more complicated ones such as open-ended, philosophical and subjective questions.

In the second level the information seeker desires specific meaning which is contextually and socially constructed. Meaning is created by the information seeker and in this process contextual elements are very important. In the third level, the information seeker wishes to find the truth about something specific, which requires deep understanding, evaluation and verification. Finally, in the top level, people look for wisdom which gives them a unique understanding of a situation, and can provide helpful advice to deal with puzzling circumstances. Figure 1 shows information seeking for different purposes.

\section{Levels of Information Seeking}

Information seeking can take place in different levels. In terms of the diversity, the broadest context is everyday life information seeking for keeping things in order (Savolainen, 1995). According to Savolainen's theory, in the context of everyday life, people require information to solve various problems, ranging from health-related issues to buying a new house. In this multi-layered and complicated setting, their information source preference and information seeking patterns are socially constructed and influenced by their psychological characteristics. Therefore, the context plays a pivotal role in the process. The focal point of Savolainen's model is the two concepts of way of life (order of things) and mastery of life (keeping things in order). The first one refers to the way people make sense of what is going on in their everyday tasks, interactions and behaviours to consider events as normal. A number of elements impact on this process, such as the structure of time budget and the consumption models that people perceive as normal to allocate time and energy for various activities including leisure and hobbies. The second concept, mastery of life, requires an active approach to put things in order, and in the way they should be. Therefore, it necessitates active problem-solving abilities and information seeking skills embedded into the steps toward the optimal situation.

This paper considers everyday life context as the first level which includes personal information which everyone wants to keep in order. The second level includes work-related information seeking for dealing with different work matters. Various kinds of information that people require to perform their work duties locate in this category. The third level is hobbyrelated information seeking which is about what people choose to do in their free time and is based on their personal interests.

Figure 2 shows different levels of information seeking in daily life and beyond. The nature, necessity and urgency of information are very diverse in different levels. As a result, the motivations of information seekers are also varied. Everyday life matters are typically 
ordinary, familiar, regular, conventional, routine, repetitive, mundane, predictable, uninteresting and unchanging. In contrast, information related to the higher levels of life is usually interesting, unfamiliar, irregular, novel, original, occasional, special, innovative, exceptional, exciting, unpredictable, and changing (Kari \& Hartel, 2007). This paper calls this kind of information transcendental information.

\section{DEFINITION OF TRANSCENDENTAL INFORMATION}

Transcendental information is a subjective and contextual concept, which means that no information item is transcendental by nature. However, the users' purposes and motivations in a context may elevate it to the transcendental level. Hence, the information people search for to deal with the higher levels of realities, such as philosophical, intellectual, poetic, spiritual, epical or aesthetic issues, as well as hobbies, serious leisure and volunteer activities, are examples of transcendental information.

For example, when someone asks about the real meaning of happiness or the ultimate purpose of life, he or she is dealing with transcendental information because such questions are not part of mundane everyday life. In fact, spending time on them eats into his or her time for performing daily tasks! Though there is no single information item which can answer such questions adequately, relevant information simply provides new insights and understanding of the issue. Further, nobody expects any immediate benefit out of this attempt. Nevertheless, people still keep searching because of the joy and fascination experienced in this journey. This is an example of transcendental information with a philosophical spirit. There are other forms as well. For instance, when people who are interested in art works look for artistic information, they are not expecting to find information that can solve a specific problem. They keep searching to satisfy their aesthetic desires.

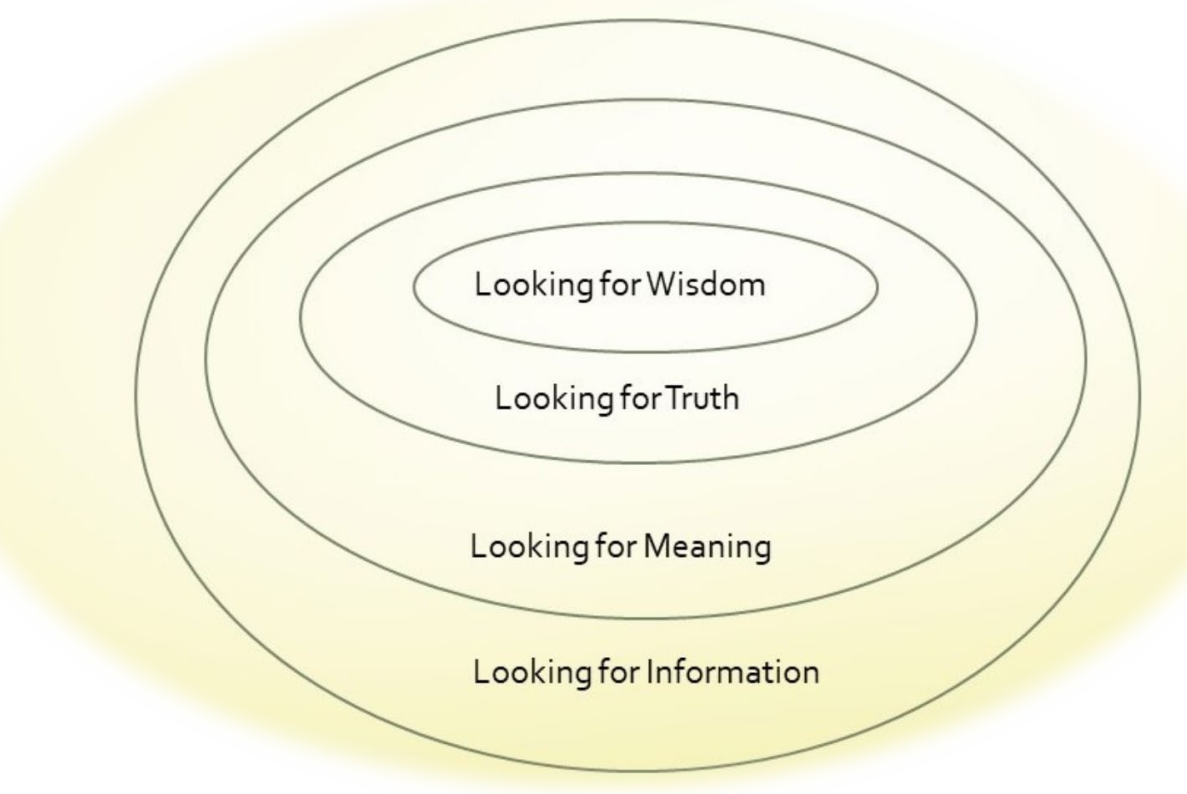

Figure 1. Information seeking for different purposes 


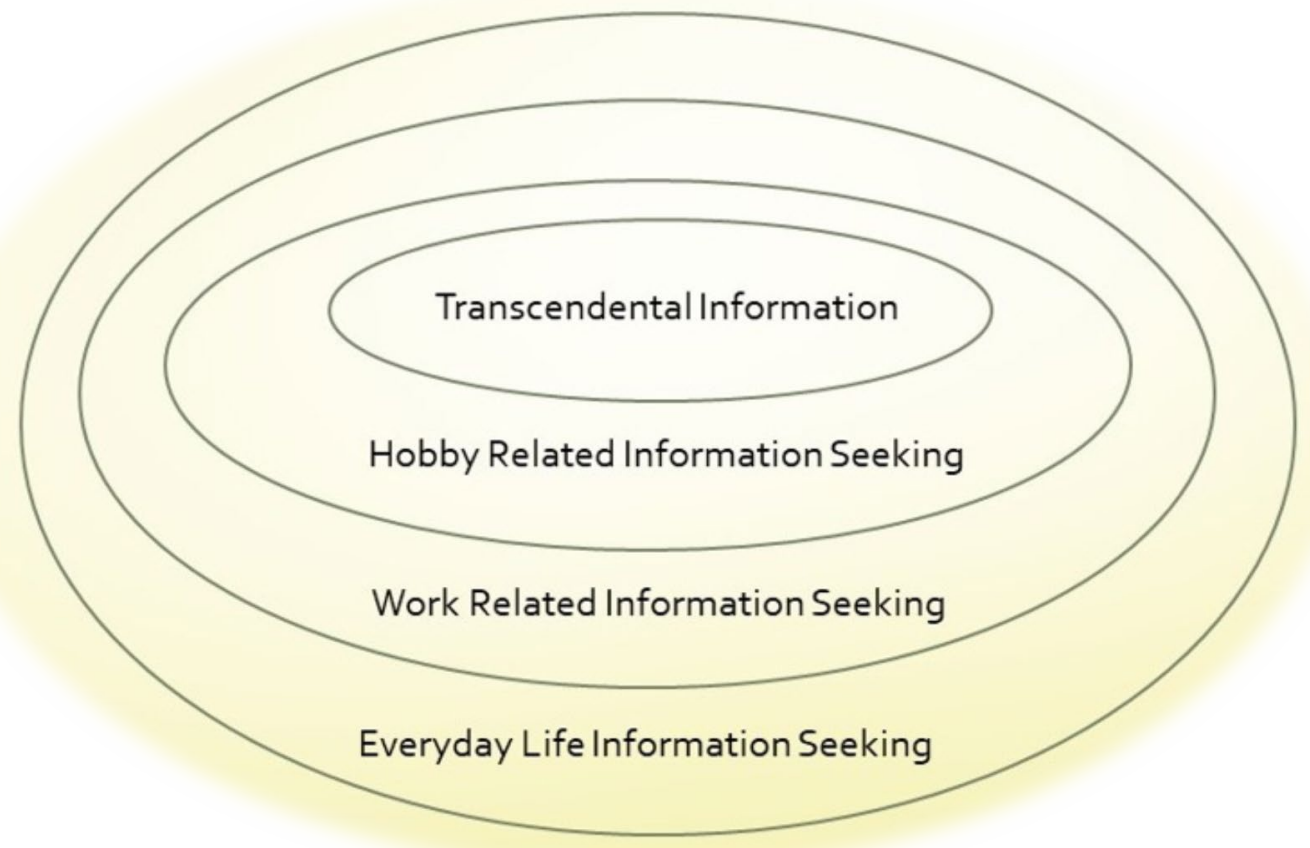

Figure 2. Levels of information seeking in daily life activities and beyond

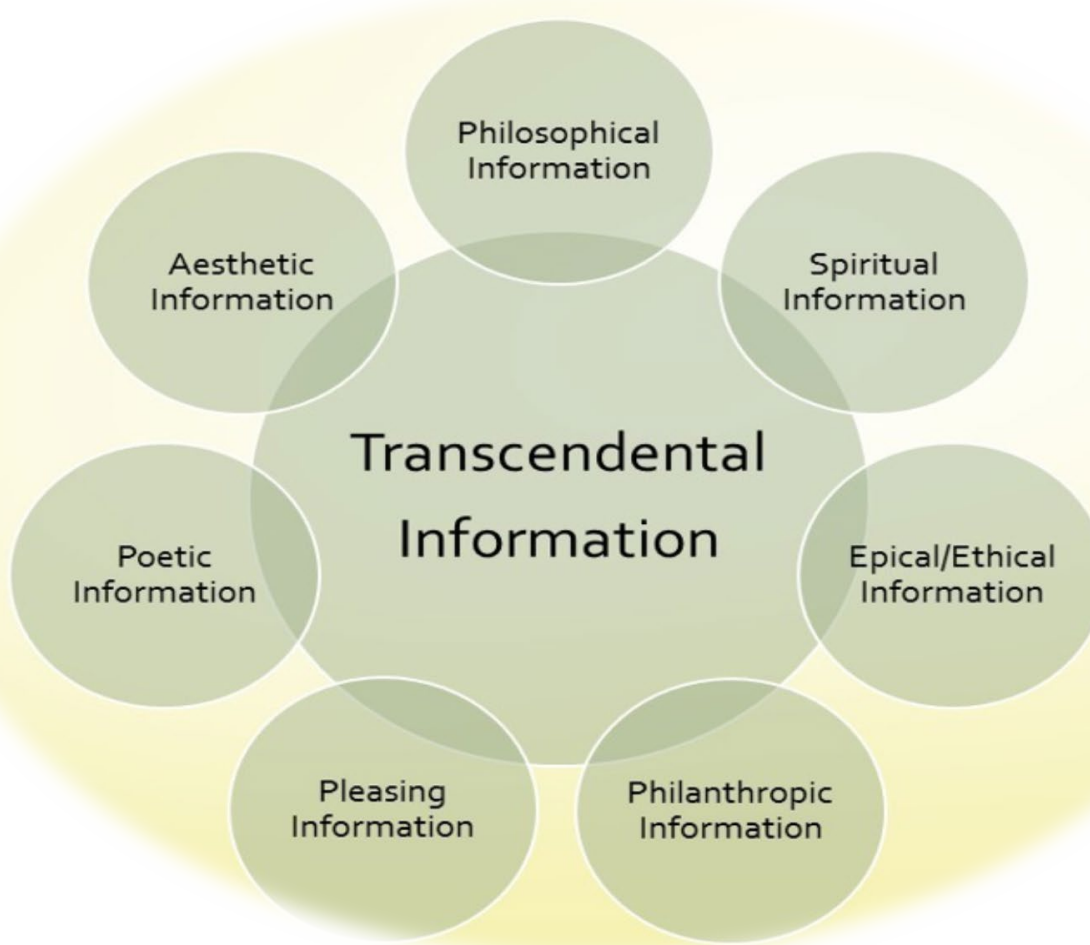

Figure 3. Various kinds of transcendental information 
In terms of format, transcendental information may exist in a wide range of media both in the textual and non-textual form including music, poetry, paintings, calligraphy and artistic objects. Moreover, information about one topic might exist in different resources. For example, someone who is interested in fine arts might see a beautiful painting at a gallery and then decide to look for information about the painter's biography without any intention of solving a problem, making money, or gaining any form of benefit. The pleasure and joy of seeking and finding relevant information about an interesting topic is the main motivation for this person which plays a key role in this process. Basically, in this and similar scenarios, the sheer joy of discovering information motivates the information seekers to explore an area that they find attractive and fascinating.

Looking for transcendental information usually requires a combination of explicit and tacit knowledge. This is because transcendental information has a dynamic and multi-faceted nature, and may appear in different formats. In terms of essence, it has aesthetic and artistic properties. Information resources about music, painting, calligraphy, architecture, sculptures are examples in this category. In terms of format, this kind of information appears mainly as either textual, non-textual or embedded information. For example, information about a wellknown sculpture exists both as embedded and text-based formats. Obviously, for someone who is an expert in fine arts, the physicality of the sculpture is full of embedded information. Also, all the resources published on it, provide information. Regarding the social sphere, transcendental information usually exists in altruistic and philanthropic settings. People who seek information about charities have philanthropic purposes which are again beyond everydayness. Regarding the scope, transcendental information is mainly holistic. For example, information about philosophical concepts, such as loneliness, generosity, wellbeing, ageing, illness, death and meaning of life, are basically timeless and placeless. In addition, most of the time transcendental information has a poetic or imaginative expression. What someone learns from classic poetry comes under in this category. As for the potential significance, transcendental information is generally meaningful and relevant to life's ultimate concerns such as liberty, joy, happiness, morality and kindness.

Regarding the common feelings related to the transcendental information, it is mostly pleasurable and profound, and people enjoy searching and sharing it. Finally, regarding its impact, it normally has an informative and inspiring impression. For example, an inspirational lecture which inspires us to make changes in our lifestyle falls under this category. Figure 3 illustrates the different types of transcendental information.

\section{DISCUSSION AND CONCLUSION}

In the past decades, information science scholars have mostly focused on the negative and problematic situations in their studies on information needs and information seeking, collecting, accessing, sharing, using, avoiding and so on. The overall assumption was that people only look for information when there is a problem that must be fixed, or when there is a gap in their knowledge about something that must be filled with new information. Of course, this is true most of the time, but not always. Researchers should also look at the other side of the coin.

There is a similar tradition of focusing on the negative sides of life in other disciplines such as psychology and organisational behaviour studies over the past decades. For example, in the field of organisational behaviour, there are many research papers on coping with stress, damage control, dealing with job burnout, lack of job satisfaction, extended work hours and 
conflict management. These issues which are associated with negative feelings and emotions seem more urgent and important, and called for immediate action.

However, the dominance of negative feelings and prevalence of various problems should not stop us from examining the positive sides of life. There is a need to move towards a balanced view. In the field of information science, and information behaviour in particular, researchers should explore the joyful and pleasant aspects of information behaviour as well. When people look for various forms of entertaining information to basically enjoy their life and spend time on delightful opportunities, they look for various forms of transcendental information. The nature of this kind of information is also unique and makes it very special for scholars in this discipline.

\section{FURTHER RESEARCH}

This paper suggests a number of themes for further research in the information behaviour field. A number of research questions based on this paper can be addressed in future qualitative, quantitative or mixed methods studies. The first theme is about exploring the significance of transcendental information in our network society in the era of social media and how significant transcendental information is, in our contemporary society. Also, there is a need for empirical data to determine how transcendental information is different from other kinds of information in various contexts, how transcendental information needs are different from practical or ordinary information needs, and what factors affect transcendental information seeking and sharing.

The second theme is about exploring real experiences of information seekers in this context to gain a deeper understanding of their main motivations and purposes for searching transcendental information and also their successes and failures during and at the end of the process. Some qualitative studies might be useful for understanding how people usually seek, browse, organise and share transcendental information and how the various social settings promote or hinder creation and sharing of transcendental information. Finally, it would be useful to find out how researchers use transcendental information as a conceptual framework to gain broader or deeper understanding of human information behaviour. For example, studying possible links between transcendental information and information encountering or serendipitous information access (Erdelez, $2004 \& 2005$ ) is a promising research direction.

\section{ACKNOWLEDGEMENTS}

This paper is part of a research project on human information behaviour in the context of serious leisure. The project was funded by the Faculty of Arts and Education at Charles Sturt University, Australia. The author also would like to thank the anonymous referees for their constructive comments and suggestions.

\section{REFERENCES}

Belkin, N.J. (1980). Anomalous states of knowledge as a basis for information retrieval. Canadian Journal of Information Science, 5(1), 133-143.

Belkin, N.J. (1978). Progress in documentation: Information concepts for information science. Journal of Documentation, 34(1), 55-85.

Belkin, N.J. (2005). Anomalous state of knowledge. In K.E. Fisher, S. Erdelez, \& L. McKechnie (Eds.), Theories of Information Behavior (pp. 44-48). Information Today. 
Bowness, J. (2020). Highland games as serious leisure: Becoming a master athlete. Leisure Studies, 39(2), 238-250.

Case, D.O., \& Given, L.M. (2016). Looking for information: A survey of research on information seeking, needs and behaviour ( ${ }^{\text {th }}$ ed.). Emerald Group Publishing Limited.

Caldwell, L.L. (2005). Leisure and health: Why is leisure therapeutic? British Journal of Guidance \& Counselling, 33(1), 7-26.

Chang, L.C. (2017). Relationships of providing and receiving leisure social support to stress in older adults. Leisure Studies, 36(4), 519-529.

Cheng, E., Stebbins, R., \& Packer, J. (2017). Serious leisure amongst older gardeners in Australia. Leisure Studies, 35(4), 505-518.

Delello, J.A., \& McWhorter, R.R. (2017). Reducing the digital divide connecting older adults to iPad technology. Journal of Applied Gerontology, 36(1), 3-28.

Dervin, B. (1983). An overview of sense-making research: Concepts, methods and results. Presented at the Annual Meeting of the International Communication Association 1983. https://www.ideals.illinois.edu/bitstream/handle/2142/2281/Dervin83a.htm

Dervin, B. (1992). From the mind's eye of the user: The sense-making qualitative-quantitative methodology. In J.D. Glazier, \& R.R. Powell (Eds.), Qualitative Research in Information Management (pp. 61-84). Libraries Unlimited.

Dervin, B. (1998). Sense-making theory and practice: An overview of user interests in knowledge seeking and use. Journal of Knowledge Management, 2(2), 36-46.

Erdelez, S. (2004). Investigation of information encountering in the controlled research environment. Information Processing \& Management, 40(6), 1013-1025.

Erdelez, S. (2005). Information encountering. In K.E. Fisher, S. Erdelez, \& L. McKechnie (Eds.), Theories of Information Behaviour (pp. 179-184). Information Today.

Falcous, M. (2017). Why we ride: Road cyclists, meaning, and lifestyles. Journal of Sport and Social Issues, 41(3), 239-255.

Fulton, C. (2009). The pleasure principle: The power of positive affect in information seeking. Aslib Proceedings, 61(3), 245-261.

Fulton, C. (2016). The genealogists' information world: Creating information in the pursuit of a hobby. Journal of Multidisciplinary Research, 8(1), 85-100.

Fulton, C. (2017). Urban exploration: Secrecy and information creation and sharing in a hobby context. Library \& Information Science Research, 39(3), 189-198.

Gorichanaz, T. (2015). Information on the run: Experiencing information during an ultramarathon. Information Research, 20(4). http://InformationR.net/ir/20-4/paper697.html

Gorichanaz, T. (2017). There is no shortcut: Building understanding from information in ultrarunning. Journal of Information Science, 43(5), 713-722.

Hartel, J. (2010). Managing documents at home for serious leisure: A case study of the hobby of gourmet cooking. Journal of Documentation, 66(6), 847-874.

Hartel, J. (2014). An interdisciplinary platform for information behaviour research in the liberal arts hobby. Journal of Documentation, 70(5), 945-962.

Heo, J., Ryu, J., Yang, H., \& Kim, K.M. (2018). Serious leisure and depression in older adults: A study of pickleball players. Leisure Studies, 37(5), 561-573.

Hershkovitz, A., \& Hardof-Jaffe, S. (2017). Genealogy as a lifelong learning endeavour. Leisure, 41(4), 535-560.

Iwasaki, Y. (2007). Leisure and quality of life in an international and multicultural context: What are major pathways linking leisure to quality of life? Social Indicators Research. 82(2), 233-264. 
Jones, I., \& Symon, G. (2001). Lifelong learning as serious leisure: Policy, practice, and potential. Leisure Studies, 20(4), 269-28.

Kari, J., \& Hartel, J. (2007). Information and higher things in life: Addressing the pleasurable and profound in Information Science. Journal of the American Society for Information Science and Technology, 58(8), 1131-1147.

LaPlante, A., \& Downie, J. (2006). Everyday life music information-seeking behaviour of young adults. In K. Lemström, A. Tindale, \& R. Dannenberg (Eds.), Proceedings of the Seventh International Conference on Music Information Retrieval (ISMIR) 2006, Canada (pp. 381-382). http://www.Webcitation.org/6TuDI5d9u

Lee, C.P., \& Trace, C.B. (2009). The role of information in a community of hobbyist collectors. Journal of the American Society for Information Science and Technology, 60(3), 621-637.

Lee, C., \& Payne, L.L. (2016). Experiencing flow in different types of serious leisure in later life. World Leisure Journal, 58(3), 163-178.

Lee, K. (2020). Serious leisure is social: Things to learn from the social world perspective. Journal of Leisure Research, 51(1), 77-87.

Lee, K., \& Ewert, A. (2019). Understanding the motivations of serious leisure participation: A self-determination approach. Annals of Leisure Research, 22(1), 76-96.

Lee, S., McMahan K., \& Scott, D. (2015). The gendered nature of serious birdwatching. Human Dimensions of Wildlife, 20(1), 47-64.

Lee, Y., \& Kim, M. (2018). Serious leisure characteristics of older adult volunteers: The case of an international sporting event. World Leisure Journal, 60(1), 45-57.

Lim, R. (2020). Monetizing serious leisure: A grounded study of fashion blogshops. Journal of Leisure Research, 51(1), 88-106.

Løseth, K. (2018). Knowledge development in adventure tourism businesses-the influence of serious leisure. Annals of Leisure Research, 21(5), 575-591

Margree, P., MacFarlane, A., Price, L., \& Robinson, L. (2014). Information behaviour of music record collectors. Information Research, 19(4). http://InformationR.net/ir/194/paper652.html

Miller, E. (2018). My hobby is global warming and peak oil: Sustainability as serious leisure. World Leisure Journal, 60(3), 209-220.

Rahikainen, K. (2020). Climbing as a lifestyle sport and serious leisure in China. Leisure/Loisir, 44(2), 175-197.

Ryu, J., \& Heo, J. (2017). Relationships between leisure activity types and well-being in older adults. Leisure Studies, 37(3), 331-342.

Savolainen, R. (1995). Everyday life information seeking: Approaching information seeking in the context of 'way of life'. Library \& Information Science Research, 17(3), 259-294.

Savolainen, R. (2007). Information source horizons and source preferences of environmental activists: A social phenomenological approach. Journal of the American Society for Information Science and Technology, 58(12), 1709-1719.

Scott, D., \& Lee, J.H. (2010). Progress, stability, or decline? Sociological mechanisms underlying change in specialization among birdwatchers. Leisure Sciences, 32(2), 180194.

Shuker, R. (2004). Beyond the 'high fidelity' stereotype: Defining the (contemporary) record collector. Popular Music, 23(3), 311-330.

Shupe, F.L., \& Gagné, P. (2016). Motives for and personal and social benefits of airplane piloting as a serious leisure activity for women. Journal of Contemporary Ethnography, 45(1), 85-112. 
Simon, H.A. (1955). A behavioural model of rational choice. Quarterly Journal of Economics, 69, 99-118.

Skov, M. (2013). Hobby-related information-seeking behaviour of highly dedicated online museum visitors. Information Research, 18(4). http://www.informationr.net/ir/184/paper597.html

Stebbins, R.A. (1982). Serious leisure: A conceptual statement. Pacific Sociological Review, $25,251-272$.

Stebbins, R.A. (1992). Amateurs, professionals and serious leisure. McGill-Queen's University Press.

Stebbins, R.A. (2001). Serious leisure. Society, May/June 38(4), 53-57.

Van Dijk, J., \& Hacker, K. (2003). The digital divide as a complex and dynamic phenomenon. The Information Society, 19, 315-326.

Zipf, G.K. (1949). Human behaviour and the principle of least effort. Addison-Wesley. 